summaries of the main historical controversies. It directs attention, at least, to the need to widen and deepen and experiment in the study of intellectual history. As a piece of popularization it is enterprising, efficient, and as good as most. It is not more than that.

D. TномsоN

\section{A TEXT-BOOK OF SURFACE CHEMISTRY}

Physical Chemistry of Surfaces

By Arthur W. Adamson. Pp. xiv +629 . (New York: Interscience Publishers, Inc.; London: Interscience Publishers, Ltd., 1960.) 96s.

PROF. ADAMSON has written a very useful textbook of surface chemistry, well balanced, full, and as up to date as anyone is likely to achieve in these days of over-voluminous and often hasty publication. It covers most of the field, including chapters on capillarity, the thermodynamics of liquid-vapour interfaces, surface films on liquids, electrical aspects of surfaces, and long-range forces. Five chapters deal with solid surfaces, one being a brief introduction to chemisorption and catalysis; and in three more, various practical applications, including wetting and detergency, flotation of minerals, emulsions and foams, and friction and lubrication, are competently discussed.

Very sensibly, the author has made good use of several earlier books, and he has added, and usually succeeded in satisfactorily incorporating, a very large amount of later work. The book is written primarily for first-year graduate students in American universities, but it should also be valuable to senior undergraduates and to anyone desiring to learn the principles, and many of the details and applications, of the subject. Many, indeed, who have carried out considerable research on surfaces can learn much from this book, in those parts of surface chemistry in which they are not specialists.

The book is also remarkably clearly written, with numerous useful analogies : for example, the difficulty of defining the area of a surface is compared with the difficulty of deciding what should be taken as the coast-line of Maine. There are a number of problems for the reader to work out at the end of many of the chapters : some of these are ingenious, and admirably suited to test the student's understanding.

I have few criticisms: perhaps there are more mistakes in historical matters, assignment of priority in discovery, dates, and spelling of names, than might have been expected : but once detected, these can easily be rectified in future printings. In places, particularly in discussing heterogeneous catalysis, he follows the modern fashion of attaching names to theories and mechanisms, and these are not always those of the originators. Few people realize that it was Langmuir who, in 1922 , published quite detailed and well-worked-out kinetics of catalytic oxidation, assuming reaction between adsorbed atoms of oxygen and molecules colliding from the gas phase: yet in this book, as unfortunately in much current literature, another name is given to this mechanism while Langmuir's name is attached to a mechanism which, so far as I am aware, he did not advocate. Too frequent attachment of names, according to current and sometimes local fashion rather than historical fact, renders a large majority of papers unreadable to anyone outside the immediate circle of specialists to which the author happens to belong, and should be avoided if possible in text-books.

Apart from these quite minor blemishes, Prof. Adamson has made a most valuable contribution to the literature of, and education in, surface chemistry, and deserves hearty congratulation. The same cannot be said of the publishers, who have fixed a price that may well put the book out of reach of large numbers who would profit by owning it.

N. K. ADam

\section{ADVANCES IN INORGANIC CHEMISTRY}

\section{Advances in Inorganic Chemistry and Radio- chemistry}

Vol. 2. Edited by H. J. Emeléus and A. G. Sharpe. Pp. viii + 392. (New York: Academic Press, Inc.; London: Academic Press, Inc. (London), Ltd., 1960.) 12 dollars.

THE titles of the reviews in this volume are as follows: "Stereochemistry of Ionic Solids", by J. D. Dunitz and L. E. Orgel ; "Organometallic Compounds" by J. Eisch and H. Gilman; "Fluorinecontaining Compounds of Sulphur" by G. H. Cady ; "Amides and Imides of the Oxyacids of Sulphur" by M. Becke-Goehring; "Halides of the Actinide Elements" by J. J. Katz and I. Sheft ; "Structures of Compounds Containing Chains of Sulphur Atoms" by O. Foss ; "Chemical Reactivity of the Boron Hydrides and Related Compounds" by F. G. A. Stone ; and "Mass Spectrometry in Nuclear Chemistry" by H. G. Thode, C. C. McMullen and K. Fritze.

From the long-term point of view, the most important articles are probably the first two, which attempt explanation as well as summary. The chapter by Dunitz and Orgel should be read by anyone professing a knowledge of structural inorganic chemistry. Three of the other chapters are devoted to various aspects of the chemistry of sulphur and reflect the current great interest in the chemistry of the elements of the second short row of the Periodic Table-although it is rather unfortunate that there is some overlap between the article on sulphur acid amides and a recent review on sulphur-nitrogen chemistry in Progress in Inorganic Chemistry. The chapter on mass spectrometry is devoted largely to the study and theory of fission yields. From the point of view of physical techniques this volume has two chapters devoted to results derived by X-ray crystallography. This should emphasize that the only absolute method of structural determination is by crystallography, and it is to be hoped that these reviews will stimulate further the interest of crystal. lographers in the structures of inorganic compounds.

Both in the standard of articles and of production, this volume is fully up to the high standard of the first of the series. The general state of health of inorganic chemistry is shown by its apparent ability to support both this series and the parallel series of Progress in Inorganic Chemistry. There is a risk that there will soon be almost as many chemists writing reviews as are carrying out original work, but at the moment Adrances in Inorganic Chemistry and Radiochemistry is proving an extremely useful and informative series.
D. W. A. Sharp 